\title{
Type 2 (Non-Insulin-Dependent) Diabetes - An Epidemiological Overview
}

\author{
P.Zimmet \\ WHO Collaborating Centre for the Epidemiology of Diabetes Mellitus, Royal Southern Memorial Hospital, Melbourne, Australia
}

Summary. Despite the use of a wide range of different methodologies and diagnostic criteria, epidemiological studies have shown that Type 2 (non-insulindependent) diabetes has a global distribution and its prevalence varies from country to country, in different ethnic groups in the same country, and between the same ethnic group undergoing internal or external migration. Rural-urban and migration studies indicate that change towards a 'Westernized' lifestyle is associated with a dramatic increase in the prevalence rates for Type 2 diabetes. Between populations, comparisons are confounded by a wide range of different ascertainment rates, survey methodologies, and diagnostic criteria for diabetes. However, low prevalence rates for Type 2 diabetes are seen in Eskimos and populations of the Far East, while the highest are seen in American Indians, urbanized Pacific Island populations, and migrant Asian Indians. Available evidence suggests that these latter groups have a genetic susceptibility to Type 2 diabetes ('diabetes genotype') and that the disease is unmasked by environmental factors. There appears to be a spectrum of interaction between genetic and environmental factors - in certain populations the genetic role may be more important than environmental, or vice versa. Epidemiological studies, apart from their value in population screenings and case-finding, have contributed to the new classification and diagnostic criteria for diabetes and our understanding of risk factors and host characteristics in the aetiology of Type 2 diabetes.

Key words: Type 2 diabetes, epidemiology, genetics, environmental factors, ethnic groups, migrants, rural urban comparisons.

Epidemiological studies relating to diabetes mellitus are playing an increasingly important role. The epidemiology thrust has gathered momentum as diabe- tologists turn to these studies to gain further understanding of aetiological mechanisms, and of the natural history of diabetes and its complications. Perhaps the best known example is the Pima Indian study - a systematic longitudinal study that has continued to provide a wealth of information about Type 2 (noninsulin-dependent) diabetes [1].

Although the thought of epidemiology has always produced a yawn as far as apparent interest is concerned, natural phenomena such as the Pima [1] and Nauru [2,3] situations should really be called a 'diabetologist's delight'. Nature itself provides a number of experimental situations for the study of diabetes all over the globe. Therefore, how could a discipline that takes diabetologists to the Caribbean, the Arizona desert, exotic Pacific islands, the Arctic, Far East, and the Australian outback present such a drab front? These regions now provide a number of unique situations where diabetes can be studied. Some of the specific features which can be studied in these populations include: 1) modernization of lifestyle of a population in situ; 2) rural to urban shifts of population providing the opportunity to study populations in a traditional-living and later urban setting (internal migration);3) situations where several ethnic groups live in the same physical environment, thus providing the opportunity to study the extent that genetic susceptibility to diabetes might play in diabetes prevalence in the population; 4) migration of certain groups, e.g. Asian Indians, to other countries (external migration).

Thus, the epidemiologist is provided with unique opportunities to study factors that may lead to the development of diabetes and its complications. It is important to emphasise that in many instances these environmental changes have been telescoped into relatively short-time frameworks, i. e. one or two decades. In contrast, the opportunity to evaluate these factors in our Western society has been limited because social 
and environmental changes have taken place over much longer time-periods, allowing more time to adjust to them.

Many of the earlier reports of diabetes prevalence in communities do not clearly distinguish between Type 1 (insulin-dependent) and Type 2 rates. However, $85 \%-90 \%$ of diabetics in developed countries suffer from Type 2 diabetes. On the other hand, Type 1 diabetes is rare in many populations [4] so that stated diabetes prevalence rates do, in general, reflect the frequency of Type 2 diabetes. For an account of the epidemiology of Type 1 diabetes, the reader is referred to a recent comprehensive review by Gamble [5].

\section{Problems in Epidemiological Methodology for Diabetes Prevalence and Incidence Studies}

The recent reports from the National Diabetes Data Group [6] and World Health Organization [7] have underlined the heterogeneity within diabetes. Based on this, we now have a more rational classification and definition of diabetes and impaired glucose tolerance. However, the vast majority of studies were performed before the new consensus on methodology and criteria was reached. Therefore, there are considerable problems and pitfalls in trying to review critically the mass of information available.

Diabetes has been referred to as the 'geneticist's nightmare' [8]. If epidemiologists have nightmares about diabetes, then they are the result of the wide range of methodologies and diagnostic criteria that have been used in epidemiological studies of diabetes prevalence and incidence. Most of the prevalence data from the various studies discussed below are based on different sampling techniques, different screening procedures and different diagnostic criteria for diabetes. Some of the major problems that occur in reviewing work in diabetes epidemiology are:

1) Sampling method: Some studies have used a random sample of the population and others have attempted cluster sampling. Age groups tested have varied widely often failing to take into consideration the fact that age structures of populations are different. Developing countries usually have very young populations when compared with industrialized nations. Furthermore, ascertainment varies considerably and the representiveness of studies with low response rates may be called into question.

2) Method of screening: In some studies the population has been screened to detect likely candidates for diabetes, and these are subjected to a formal oral glucose tolerance test. The problem with certain screening methods is that they may miss some people who will prove diabetic with an oral glucose tolerance test.
This is particularly true for screening using glycosuria [4]. Furthermore, the method used for oral glucose tolerance tests varies widely [4]. Glucose loads used vary from 50,75 or $100 \mathrm{~g}$ to loads computed from body weight or body surface area. The diagnosis of glucose intolerance may be based on a whole range of different diagnostic criteria [9]. Interpretation and comparison is complicated by the use of whole blood glucose in some studies and plasma or capillary glucose in others. The recent change from $\mathrm{mg} / \mathrm{dl}$ to $\mathrm{mmol} / \mathrm{l}$ has further added to the confusion, particularly with respect to rounding off $\mathrm{mmol} / \mathrm{l}$ values after conversion from $\mathrm{mg} / \mathrm{dl}$.

3) Inclusion of known diabetic subjects: In some studies, known diabetic subjects on treatment are included irrespective of the level of their screening plasma glucose, whereas in other studies, they are included only if their plasma glucose falls within the diabetic range. In addition, the new diagnostic criteria are set higher than earlier recommended criteria. Thus, many of the diabetics - both known and new in these early surveys would now fall into the class of impaired glucose tolerance.

4) Use of hospital admission and mortality data: Although well-collected data on diabetic admissions and mortality have their place as an index of diabetes prevalence, there are a large number of factors which limit their sensitivity and specificity. These shortcomings were reviewed in detail by the late Kelly West [4]. The variations in collection of these data from country to country limit their usefulness in a review such as this, so that the main emphasis will be placed on prevalence and incidence studies.

\section{Prevalence of Type 2 Diabetes}

Even allowing for differences in methodology and diagnostic criteria, there are marked differences in the prevalence of Type 2 diabetes between countries, between different ethnic groups in the same country, and between the same ethnic group undergoing internal or external migration. As far as we can tell, it seems that Type 2 diabetes was rare in many populations, particularly for those having a traditional-lifestyle $[10,11]$. With progressive modernization of lifestyle, Type 2 diabetes has become prevalent and, indeed, almost endemic in certain American Indian [10], Pacific island [11], and Asian populations [12]. Type 1 diabetes is rare or unknown in these populations.

Even today, there are traditional-living Polynesian populations where Type 2 diabetes is unknown or rare, yet urbanized subjects of the same ethnic group show exceptionally high diabetes prevalence rates $[11,13,14]$. Thus, there may be an underlying 
genetic susceptibility to Type 2 diabetes in these populations which is unmasked by environmental factors [11]. Different genetic factors and environmental influences operate in the pathogenesis of Type 1 diabetes which predominantly appears to be a disease of Caucasoids [15]. The change in Type 2 diabetes prevalence can be understood within the framework of epidemiological transition - a concept which is concerned with the changing patterns of health and disease in relation to change in demographic, social, and economic indices in different population groups [16].

Although only a few studies have used identical methodology and diagnostic criteria, there is sufficient similarity between some studies for comparison. Table 1 provides a selection of results from various countries and ethnic groups where cautious comparison is possible.

The lowest prevalence rates $(<2 \%)$ have occurred in Eskimos [17], Alaskan Athabascan Indians [18], the Indian sub-continent [19], and populations of the Far East. This latter group includes Japan [20], Indonesia [21], and Chinese in the Peoples Republic of China [22] and Singapore [23]. These rates are slightly lower than those reported in Australian and New Zealand Caucasoids -2.3 and $2.8 \%$ respectively $[13,24]$. The latter studies do include some patients with Type 1 diabetes, but this would not affect the results materially. Differences in methodology may make the differences in prevalence more apparent than real.

The highest diabetes prevalence rates reported in the literature (approximately 35\%) are in the American Pima Indians [1] and in the Micronesian population of Nauru [2]. Prevalence rates are also quite high in a number of other American Indian populations $[10,25,26]$, other Pacific island populations - Western Samoa [14], Tonga [27], Australian aboriginals [28], Fiji Indians [30], certain groups in Papua New Guinea [29], and other migrant Indian communities in Singapore [22], Malaysia [31] and South Africa [32], and in the Maltese population [33]. There are also reports of high diabetes prevalence rates in certain Central American countries [34]. Recently, Stern et al. have reported a $10 \%$ diabetes prevalence rate in Mexican Americans [35]. In this latter study, the diagnosis of diabetes was based on a fasting plasma glucose $\geqslant$ $140 \mathrm{mg} / \mathrm{dl}$ - a more stringent criterion than most of the above-mentioned studies.

The high diabetes prevalence rates in migrant Indian populations provide a very interesting situation with respect to the epidemiology of Type 2 diabetes. Whereas reported diabetes prevalence rates for the Indian sub-continent are 1.2\% (rural) and 2.0\% (urban) [19], prevalence rates for Indians in South Africa and Fiji are nearly ten times higher [30,32].

In 1907, Bose [36] made a rather perceptive observation at a Symposium on Diabetes in the Tropics. He stated 'What gout is to the nobility of England, diabetes is to the aristocracy of India'. Inbreeding has been suggested as a possible cause for the high diabetes prevalence in the isolated Tamil Indian population in South Africa [37] and Fiji Indians [30], but the other populations of less isolated Indians also show high diabetes prevalence rates when compared with other ethnic groups in the same locality. Diabetes has also been noted to be more prevalent in Indians in Uganda [38] and Kenya [39] than in the local African population of these countries.

A number of studies report prevalence rates in several different ethnic groups living in similar physical environments. Some of these studies are summarized in Table 2. These studies indicate that Indians have a greater susceptibility to diabetes than many other ethnic groups. Migrant Indians in South Africa [32], Trinidad [40], Singapore [23], Malaysia [31] and Fiji [30] show higher diabetes prevalence rates than the local population and in the people of the Indian sub-continent [19]. Numerous reports exist of migration studies in other ethnic groups beside the Indians. These are reviewed in detail elsewhere [12]. In the Pacific region, migrant Micronesian [12] and Polynesian populations (Wallis [12] and Tokelau [41]) show higher prevalence rates than do the sedentees.

Migration to Israel has provided many different ethnic sub-groups which have lived under widely differing environmental conditions. Cohen et al. have compared new-immigrant Yemenites and new-immigrant Kurds with old settlers of these two ethnic groups in Israel, and have found a higher prevalence of diabetes in the old settlers [42]. When this population of 'new immigrant Yemenites' was studied almost 20 years later, the diabetes prevalence was found to have increased to $11.1 \%$ from the previously low level of $0.06 \%$ [43].

Kawate et al. [44] have reported that Japanese migrants and their off-spring in Los Angeles, USA and on the islands of Hawaii have higher diabetes prevalence rates than Japanese living in Hiroshima.

In each of these situations, the role of environmental factors is likely to be very important in the development of Type 2 diabetes and this is discussed later.

\section{Is the Prevalence of Type 2 Diabetes Increasing?}

Although high diabetes prevalence rates have been reported in a number of populations which have undergone rapid acculturation, apart from the Pima Indians [45], direct evidence of a secular change in prevalence rates is lacking. Diabetes was rare in the Pima 80 years ago, and relatively uncommon 40 years ago, but by 1967 they had the highest prevalence yet recorded in the literature. In 10 years between 1967 and 
Table 1. The prevalence of Type 2 diabetes in some world populations

\begin{tabular}{|c|c|c|c|c|c|}
\hline Author/s (reference) & Country & Ethnic group & $\begin{array}{l}\text { Age } \\
\text { group } \\
\text { (years) }\end{array}$ & $\begin{array}{l}\text { Diagnostic criteria }{ }^{a, b} \\
\text { (2-h plasma } \\
\text { glucose } m m o l / l)\end{array}$ & $\begin{array}{l}\text { Diabetes } \\
\text { prevalence } \\
(\%)\end{array}$ \\
\hline Toyota et al. [20] & Japan & Japanese & $20+$ & $\geqslant 8.3 \quad(50 \mathrm{~g})$ & 1.0 \\
\hline Djokomoeljanto et al. [21] & Indonesia & Indonesian & $14+$ & $\geqslant 7.8 \quad(50 \mathrm{~g})$ & 1.5 \\
\hline Gupta et al. [19] & India & $\begin{array}{r}\text { Indian (rural) } \\
\text { (urban) }\end{array}$ & $15+$ & $\geqslant 7.8 \quad(75 \mathrm{~g})$ & $\begin{array}{l}1.2 \\
2.0\end{array}$ \\
\hline Mouratoff et al. [18] & Alaska & Athabascan Indian & $20+$ & $\geqslant 8.9(100 \mathrm{~g})$ & 1.3 \\
\hline Mouratoff et al. [17] & Alaska & Eskimo & $20+$ & $\geqslant 8.9(100 \mathrm{~g})$ & 1.9 \\
\hline Cheah and Tan [22] & Singapore & Chinese & $15+$ & $\geqslant 8.9(50 \mathrm{~g})$ & 1.6 \\
\hline Welborn et al. [24] & Australia & Caucasoid & $20+$ & $\geqslant 8.3(50 \mathrm{~g})$ & 2.3 \\
\hline Prior and Davidson [13] & New Zealand & $\begin{array}{l}\text { Caucasoid } \\
\text { Polynesian }\end{array}$ & $20+$ & $\geqslant 8.3(100 \mathrm{~g})$ & $\begin{array}{l}2.8 \\
7.5\end{array}$ \\
\hline Prior and Davidson [13] & Cook Islands & $\begin{array}{l}\text { Polynesian (rural) } \\
\text { Polynesian (urban) }\end{array}$ & $20+$ & $\geqslant 8.3(100 \mathrm{~g})$ & $\begin{array}{l}2.4 \\
5.7\end{array}$ \\
\hline Marine et al. [32] & South Africa & $\begin{array}{l}\text { African } \\
\text { Indian }\end{array}$ & $15+$ & $\geqslant 7.8 \quad(50 \mathrm{~g})$ & $\begin{array}{r}3.6 \\
10.4\end{array}$ \\
\hline Wise et al. [28] & Australia & Aborigine & $20+$ & $\geqslant 8.3 \quad(50 \mathrm{~g})$ & 11.0 \\
\hline Henry et al. [25] & USA & Cocopah Indian & $15+$ & $\geqslant 8.9(100 \mathrm{~g})$ & 19.4 \\
\hline Stein et al. [26] & USA & Cherokee Indian & $34+$ & $\geqslant 9.4 \quad(1 \mathrm{~g} / \mathrm{kg})$ & 29.0 \\
\hline Zimmet et al. [2] & Nauru & Micronesian & $15+$ & $\geqslant 8.9(75 \mathrm{~g})$ & 34.4 \\
\hline Bennett et al. [1] & USA & Pima Indian & $15+$ & $\geqslant 8.9(75 \mathrm{~g})$ & 35.0 \\
\hline
\end{tabular}

a See original paper for full criteria

b Oral glucose load for test

Table 2. Prevalence rates for Type 2 diabetes in different ethnic groups in the same country ${ }^{\mathrm{a}, \mathrm{b}}$

\begin{tabular}{|c|c|c|c|c|}
\hline Author/s (reference) & Country and eth & & $\begin{array}{l}\text { Age group } \\
\text { (years) }\end{array}$ & $\begin{array}{l}\text { Diabetes } \\
\text { prevalence }(\%)\end{array}$ \\
\hline Mouratoff et al. [18] & Alaska & $\begin{array}{l}\text { Eskimo } \\
\text { Amer Indian }\end{array}$ & $20+$ & $\begin{array}{l}1.9 \\
1.3\end{array}$ \\
\hline Zimmet et al. [30] & Fiji & $\begin{array}{l}\text { Melanesian } \\
\text { Indian }\end{array}$ & $20+$ & $\begin{array}{r}7.0 \\
14.0\end{array}$ \\
\hline Cheah and Tan [22] & Singapore & $\begin{array}{l}\text { Chinese } \\
\text { Malay } \\
\text { Indian }\end{array}$ & $15+$ & $\begin{array}{l}1.6 \\
2.4 \\
6.1\end{array}$ \\
\hline Marine et al. [32] & South Africa & $\begin{array}{l}\text { African } \\
\text { Malay } \\
\text { Indian }\end{array}$ & $20+$ & $\begin{array}{r}3.6 \\
6.6 \\
10.4\end{array}$ \\
\hline Poon-King et al. [40] & Trinidad & $\begin{array}{l}\text { Negro } \\
\text { Indian }\end{array}$ & $20+$ & $\begin{array}{l}2.5 \\
4.5\end{array}$ \\
\hline West and Kalbfleisch [31] & Malaysia & $\begin{array}{l}\text { Malay } \\
\text { Indian } \\
\text { Chinese }\end{array}$ & $30+$ & $\begin{array}{l}1.8 \\
4.2 \\
4.7\end{array}$ \\
\hline Zimmet et al. [30] & New Caledonia & $\begin{array}{l}\text { Melanesian } \\
\text { Polynesian }\end{array}$ & $20+$ & $\begin{array}{l}2.0 \\
5.8\end{array}$ \\
\hline Prior and Davidson [13] & New Zealand & $\begin{array}{l}\text { Caucasoid } \\
\text { Polynesian }\end{array}$ & $20+$ & $\begin{array}{l}2.8 \\
7.5\end{array}$ \\
\hline
\end{tabular}

a Different diagnostic criteria and age groups (see reference for details)

b Comparison should be made with caution. However, the purpose of this table is to illustrate inter-ethnic differences as the same criteria are used within each country

1977, there has been an overall $42 \%$ increase in agesex adjusted diabetes prevalence (Fig.1).

\section{Type 2 Diabetes Prevalence Rates Using New Diagnostic Criteria}

Since 1975, the Royal Southern Memorial Hospital Epidemiology Unit in Melbourne has carried out dia- betes epidemiological studies in Melanesians, Polynesians, Micronesians, and Indians in several Pacific countries. Identical methodology has been used in each study and, therefore, the results can be directly compared. Table 3 shows the results of these studies and age-standardized diabetes prevalence rates using the new WHO criteria for diabetes [7]. Rates in the Pima Indians are also shown. The highest Pacific prevalence rates were seen in Nauruans and Fiji Indians. 
Table 3. Prevalence rates (subjects 20 years and over) of Type 2 diabetes in Pacific populations surveyed by Royal Southern Memorial Hospital Melbourne Epidemiology Unit (1975-1980)

\begin{tabular}{llr}
\hline Country (Reference) & Ethnic group & $\begin{array}{c}\text { Prevalence }^{\mathrm{a}} \\
(\%)\end{array}$ \\
\hline Nauru [2] & Micronesian & 30.3 \\
Tuvalu [11] & Polynesian & 3.9 \\
Western Samoa [14] & Polynesian (rural) & 2.7 \\
& \multicolumn{1}{c}{ (urban) } & 7.0 \\
New Caledonia (mainland) [30] & Melanesian (rural) & 1.5 \\
New Caledonia (Loyalty Islands) [30] & Melanesian & 2.0 \\
Fiji [30] & Polynesian - Melanesian (mixed) & 5.8 \\
& Melanesian (rural) & 1.8 \\
& \multicolumn{1}{c}{ (urban) } & 6.9 \\
Wallis Islands [12] & Indian (rural) & 13.3 \\
USA [45] & Polynesian & 14.8 \\
\hline
\end{tabular}

a WHO Criteria (1980) for diabetes mellitus $-2 \mathrm{~h}$ plasma glucose $\geqslant 11.0 \mathrm{mmol} / \mathrm{l}$ after $75 \mathrm{~g}$ oral glucose load as well as known diabetic patients

Prevalence rates for diabetes, based on cases of known diabetes from health interviews or national registers, almost certainly understate the true situation [14]. Screening surveys done in many diverse population groups indicate that for every known diabetic, there is at least one or two undiagnosed cases [2, 21, $25,32,46]$. Harris has recently provided data that indicate there has been a tenfold increase in the prevalence of diabetes in the USA during the past 45 years [47]. These data were collected on the basis of interviews in the home during National Health surveys conducted by the United States Public Health Service.

\section{Incidence}

There are very few studies on the incidence of Type 2 diabetes where standardized and comparable methodology have been used. Hamman et al. have reviewed the major studies on diabetes incidence [48].

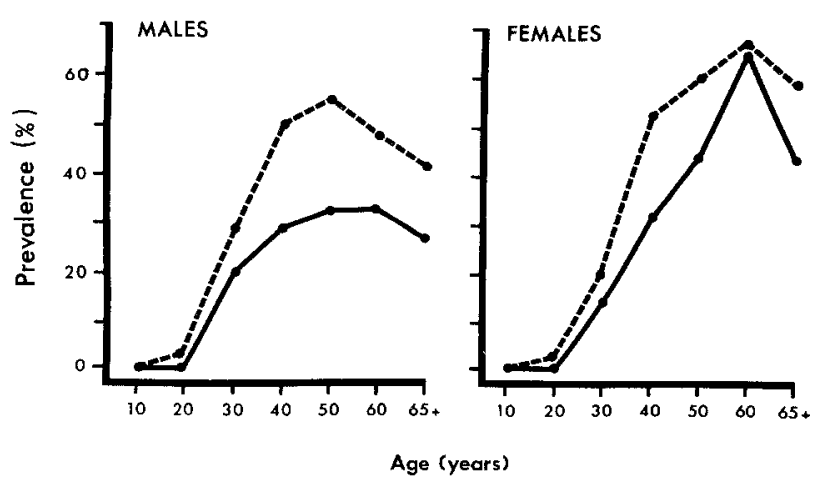

Fig. 1. Age specific prevalence of diabetes in Pima Indian males and females in $1967(-0)$ and $1977(--)$ ). (Reproduced by kind permission of Bennett \& Knowler [45].)
The wide range of ascertainment figures and diagnostic criteria make comparison pointless.

The most satisfactory methodology would be to study a fixed population at two separate points in time, and then to estimate the cumulative incidence rate within the period between the examinations. Such a study has been performed on the Pima Indians $[48,49]$. The age-sex adjusted incidence rate was 26.5 cases $/ 1000$ person years in Pimas aged 5 years or over. The Pima incidence rate was compared with that of the predominantly white American population of Rochester, Minnesota [50]. These two populations were standardized by age-sex adjustment using the census of the United States white population. Thus, the Pima diabetes incidence rate was 19 times that of a Caucasoid population. As the diagnostic criteria for diabetes were more stringent in the Pima studies, the actual difference in rates is probably greater. Using similar methodology, the Micronesian population of Nauru was found to have an incidence rate of $15.4 / 1000$ person years - a rate second only to that of the Pimas [51]. Harris has also provided data on the incidence of diabetes in the United States of America [47]. In 1936, the incidence of diabetes was $5 / 10,000$ population and in 1973 it was $29.7 / 10,000$. Although data collected in this fashion are not as reliable as community screening surveys, there is clear evidence of a large secular increase in the prevalence of diabetes in the United States (Fig. 2).

\section{Other Facets of Epidemiological Studies}

The epidemiological studies in Pimas and Nauruans have had some value in determining the cut-off points used for normal subjects, impaired glucose tolerance and diabetes in the new National Diabetes Data 


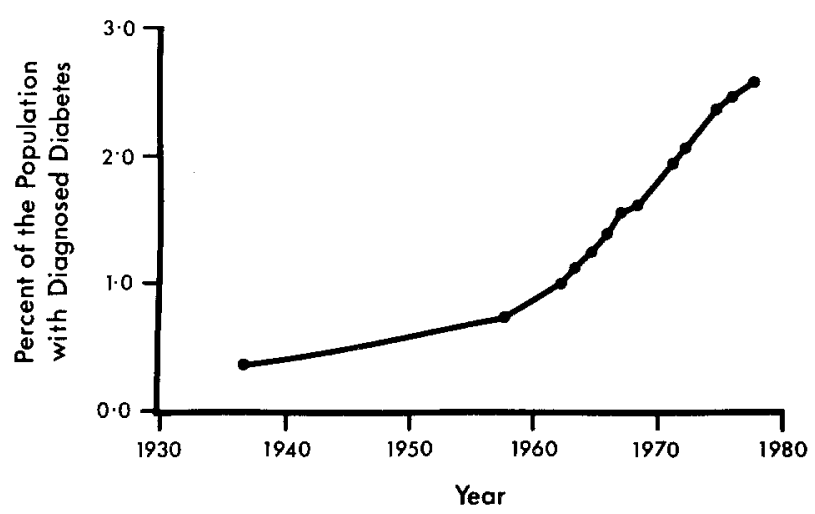

Fig. 2. Prevalence of diagnosed diabetes (United States National Health Surveys). The secular increase in prevalence of diabetes in the United States of America. (Reproduced by kind permission of Dr. M. Harris.)

group [6] and WHO [7] diagnostic criteria. Bimodality of fasting and 2-h post-load plasma glucose distributions have been demonstrated in both populations [52-54]. The cut-off plasma glucose values between the two modes were: fasting approximately $140 \mathrm{mg} / \mathrm{dl}(7.8 \mathrm{mmol} / \mathrm{l})$ and $2 \mathrm{~h}$ approximately $200 \mathrm{mg} / \mathrm{dl}(11.1 \mathrm{mmol} / \mathrm{l})$ respectively. These are the values in the new diagnostic criteria. In contrast, bimodality has not been documented in Caucasoid populations [55].

\section{Aetiological Factors for Type 2 Diabetes}

Much of the recent information has come from populations such as Pimas and Nauruans and from migration studies. The latter help to distinguish the genetic from the environmental factors causing or contributing to diseases such as diabetes. The rationale underlying migrant studies is as follows - populations move to an alien social, cultural, economic, and geographical environment and their way of life changes. They can then be compared with the same genetic group which stayed behind (sedentees). Health changes can be monitored in the migrants, compared with the sedentees or the host community, and the differences may provide important clues to specific aspects of the new and old environment which could be relevant to the pathogenesis.

\section{Genetic and Environmental Factors}

There are some general points to be made concerning the study of genetic and environmental factors in the aetiology of diabetes. First, although the major genetic susceptibility to Type 1 diabetes is HLA-linked [56, 57], genetic markers for Type 2 diabetes have yet to be defined - although some have been suggested [58-60]. Secondly, measurement of the various environmental influences is not easy. Height and weight can be measured accurately, but the relationship of these indices to obesity varies with sex, frame size, muscularity and ethnic origin. Dietary surveys are notoriously timeconsuming and difficult, particularly if characterization of individuals rather than groups is required. Furthermore, food analysis is sometimes not available for tropical foods - particularly information on simple sugar and fibre content. Data on physical activity are more difficult to collect, and various rough gradings (often based on occupation) have to be used.

\section{Genetic Factors}

As little is known of the genetic basis of Type 2 diabetes, epidemiological studies provide the potential for new information. There appears to be a varying genetic susceptibility to diabetes amongst different racial groups but, except under certain environmental conditions [11], this difference is not obvious. Migrant studies in diabetes can tell us more than the effect of environment on the disease. Many migrant communities have a higher prevalence of diabetes, not only compared with sedentees but also higher than the population of their adopted country [12]. Genetic differences have been imputed to explain this difference, although the possibility of subtle differences in lifestyle are difficult to exclude.

There are a number of instances where several ethnic groups have been studied in the same physical environment (Table 2). The differences in diabetes prevalence rates in these situations have been ascribed, in part, to differences in genetic susceptibility to diabetes [30]. However, migrant and rural/urban studies on the same ethnic group in Western Samoa [14], Puerto Rico [61], India [19] and Fiji [30] show higher diabetes prevalences in urban subjects. Consequently, the emergence of diabetes in certain migrant groups would appear to be the result of genetic-environmental interaction, with perhaps varying contributions under different circumstances.

Relevant to this is the 'thrifty genotype' hypothesis proposed in 1962 by Neel [62] and recently revised [63]. Neel found himself wondering how an apparently genetic disease with generally adverse impact on survival and reproduction, such as diabetes, could attain such a high frequency in some populations. He postulated that this high prevalence may be explained by the fact that what is now a diabetic genotype must have conferred some survival advantage at certain times in the past. Neel proposed that people with a hereditary tendency to diabetes were better able to 
store energy efficiently permitting survival under conditions of alternating feast and famine.

It is possible that this hereditary factor was a significant one in terms of preserving population numbers in response to varying food availability. As such, this genotype has been maintained selectively in those communities where widely fluctuating food availability has been present during major evolutionary periods. At the present time, this hereditary survival factor is of little use and the introduction of a plentiful and steady food supply leads to clinical diabetes. There is laboratory evidence to support this theory from the studies of Wise in sand mice [64].

At the time Neel proposed this original hypothesis, a clear clinical distinction between Type 1 and Type 2 diabetes did not exist. In addition, the original physiological basis of his hypothesis is now untenable, as the supportive evidence has, in the main, been invalidated [63]. Given this information, there is still reason to believe that Neel's hypothesis was correct, but perhaps for the wrong reasons! One of the mechanisms suggested is an over-responsive $B$ cell, i.e. a 'quick insulin trigger' which may have been an advantage in the days of feast or famine helping to ensure maximum food utilization, i.e. by promoting fat and glycogen deposition. This aspect of B cell function may be genetically determined. The evolutionary advantage was more efficient utilization of foodstuffs in feasts and famine. In time, with continual over-stimulation, the B cells may lose their capacity to respond, resulting in Type 2 diabetes.

Another hypothesis puts the emphasis on a genetically determined 'down regulation' of insulin receptors in response to repeatedly high levels of circulating insulin. Hyperinsulinaemia is well documented in a number of populations which now exhibit high Type 2 diabetes prevalence rates. These include the Pima Indians [1], Nauruans [65] and Australian aborigines [66]. Thus, 'down regulation' of the insulin receptor in the face of persistent hyperinsulinaemia may create a vicious circle whereby the B cells eventually fail in the face of loss of insulin sensitivity and the production of insulin resistance.

While it may be coincidental that the tendency towards development of hypoinsulinaemia in the above populations occurs at 2 -h post-load levels of $200-239 \mathrm{mg} / \mathrm{dl}[1,65]$, it is interesting to note that this is the region of the cut-off point of the first and second components of the bimodality noted in the Pimas and Nauruans. At 2-h plasma glucose values $<200 \mathrm{mg}$ / $\mathrm{dl}$, there is a progressive increase in the 2 -h plasma insulin, which then falls as glucose intolerance becomes more overt. It is tempting to suggest that the failure of the endocrine pancreas to respond to the glycaemic stimulus at this point leads to overt diabetes.

\section{Genetic Markers}

A discussion of genetic markers is beyond the scope of this review. Nevertheless, the ethnic differences in diabetes prevalence mentioned earlier provide suggestive evidence that certain ethnic groups have low or high genetic susceptibility to diabetes. To date, the supposed diabetic genotype has not been defined.

Strong evidence in favour of a strong genetic input into Type 2 diabetes emanates from studies of identical twins and families [58]. Monozygotic twins have much higher rates of concordance for Type 2 than Type 1 diabetes.

Pyke has suggested that the chlorpropamide alcohol flush phenomenon is a genetic marker for Type 2 diabetes [58], although this has been contested by others [67]. Owerbach and Nerup [60] have presented preliminary data on the human insulin gene and suggest that the homozygous UU genotype could be a genetic marker for Type 2 diabetes. A weak association between HLA-A 2 and Type 2 diabetes has been found in Xhosas [68] and Pimas [69], and between HLA-B 61 and Type 2 diabetes in Fiji Indians [59]. However, in Caucasoid populations, the frequencies of all the HLA antigens, including DR 3 and DR 4, do not show any significant changes in Type 2 diabetes $[70,71]$.

Extensive research is at present underway as to whether non-HLA chromosome 6 markers, e.g. glyoxylase, $\mathrm{C}^{2}$ complement, or properdin factor $\mathrm{B}(\mathrm{Bf})$ may show an association with Type 2 diabetes, although available evidence in Pacific populations does not suggest this [30].

There appears to be a spectrum of interaction between genetic susceptibility and environmental factors to produce Type 2 diabetes. In certain situations, the genetic role is much more powerful and environmental factor input is negligible, or vice versa. A good example of this is in Fiji where there are two main ethnic groups - Melanesian and Indian. A recent epidemiological survey delineated the prevalence of diabetes in these two ethnic groups in rural and urban settings. In the Melanesians, the prevalence of diabetes was low in rural dwellers, and significantly higher in city dwellers [30]. Yet in the Fiji Indian populations, the prevalence of diabetes (WHO criteria, 1980) was high (approximately 14\%) in both rural and urban communities [30]. Whilst the urban Indians live a modern lifestyle, the rural Indians come from a low socio-economic group, and are subsistence farmers engaging in heavy labour. The high prevalence of Type 2 diabetes in rural Fijian Indians is unlikely to be due to obesity, a Western-style diet, or physical inactivity. These people are subsistence farmers - less obese and more physically active than their urban 
counterparts and have a poorer diet. It seems more likely that genetic factors relating to susceptibility are much more important than environmental input in this particular community. Members of this isolated Indian community are considerably inbred and any diabetogenic gene could be potentiated, as has been suggested in a community of poor Tamil Indians in Cape Town, South Africa [37].

Diabetes incidence in the Pima Indians is strongly related to parental occurrence of diabetes, although no specific mode of inheritance has been documented [72]. Adjusted for age and obesity, incidence was 2.3 times as high in subjects with one diabetic parent and 3.9 times as high in those with two diabetic parents as in those with two non-diabetic parents. Thus, in the Pimas, heredity appears to be an important factor in the development of Type 2 diabetes.

\section{Environmental Factors}

The evidence that the same ethnic group may show a higher diabetes prevalence in an urban setting compared with rural areas emphasises the important role of environmental factors. The problem that faces the epidemiologist is which, or a combination of which, factors contribute.

Age: While age, per se, is not an environmental factor, the prevalence and incidence of Type 2 diabetes increases with age $[4,49]$. This increasing prevalence can be considered a true phenomenon having been seen in most population studies [4]. Less clear cut, and still controversial, is the question of the significance of the deterioration of glucose tolerance with age. There are two major schools of thought relating to the reported decline in glucose tolerance with age noted in population studies [73]. This first view is that it is a natural phenomenon - part of the aging process. The other view states that a progressive decline in glucose tolerance with age is due to the gradual evolution of increasing numbers of true diabetics, i.e. a pathological change. A number of studies, which are reviewed in greater detail elsewhere [73], support the latter view. However, DeFronzo has suggested that the age-related decline in glucose tolerance results from tissue unresponsiveness to insulin that occurs with aging [73].

Obesity: The 1980 WHO Expert Committee on Diabetes concluded that the most powerful risk for Type 2 diabetes is obesity [7]. The two most important aspects in assessing the role of obesity are its extent and duration [4]. Measurement of the duration of obesity presents great difficulties and there is very little reliable data with respect to Type 2 diabetes.
Medalie et al. found that being overweight (measured by body mass index) was one of the most significant variables associated with the development of diabetes in Israel [75]. In a study of the relationship of obesity and diabetes incidence in Pima Indians, Knowler et al. found that diabetes incidence was strongly related to preceding obesity [72]. They also noted, however, that the high diabetes incidence in Pimas cannot be entirely attributed to obesity.

Prevalence studies show a lesser relationship between diabetes and obesity $[12,14,61,76]$, perhaps because of the confounding influence of weight loss with the onset of the disease or with therapeutic intervention. These studies indicate that although differences in obesity between two populations can explain some of the difference in diabetes prevalence, obesity is not the only or even the main factor responsible for such differences.

Kawate et al. found that the prevalence of diabetes was higher in migrant Japanese in Hawaii than in Hiroshima, and this was independent of weight [44].

Studies of Pacific migration, e.g. the Tokelauans [41] and the Wallesiens [12] have revealed that differences in obesity do not account for all the variation in diabetes prevalence between migrants and sedentees. From comparisons between India and Indians in Malaysia and South Africa, Ahuja concluded that the difference in diabetes prevalence in Indians abroad could not be explained on the basis of adiposity [77]. Weight and height figures provided by Ahuja indicate that the mean body mass index for Indian males and females is approximately 23.8 and 23.9 respectively. These values are very similar to those we found in the Fiji Indian males (22.5) and females (23.9), yet the Fiji Indians have much higher diabetes prevalence than people in India.

Similar results are seen in rural/urban comparisons of diabetes prevalence. The marked difference in prevalence of abnormal glucose tolerance between rural and urban Western Samoan Polynesians persist after age and weight standardization of the two groups [76]. Similar findings were noted in a recent report of rural/urban comparisons of diabetes prevalence in Puerto Rican men [61].

Indentical twin studies suggest that the genetic component in Type 2 diabetes acts independently of obesity. Twin pairs are concordant for Type 2 diabetes even when their weight differs considerably and when neither twin is overweight [78].

West stressed that both the degree and duration of obesity are important variables to be considered in attempting to explain the relationship of obesity and diabetes [4]. Thus, differences in diabetes frequency between two groups of equal adiposity (or adjusted to 
the same distribution) may exist because the obesity is of longer duration in one group than the other. However, duration of obesity does not explain why the lean urban dwellers or migrants have higher rates of diabetes than the lean rural dwellers or sedentees [61, 76].

These findings suggest that there are additional powerful environmental factors in the urban lifestyle operating independently of obesity which contribute to a higher diabetes prevalence in urban dwellers and in migrants.

Physical activity: The interaction of diet, exercise and obesity is a complex one. It is difficult to isolate exercise and study it as a single factor in relation to diabetes prevalence and incidence. In addition, the quantitative measurement of physical activity is difficult and existing methods are crude. There is evidence, however, to suggest that exercise has a protective effect against the development of diabetes [4]. Rural-urban shift and migration are usually accompanied by change in levels of physical activity, almost invariably to a more sedentary pattern [12].

The rural/urban studies in Puerto Rico [61], Western Samoa [14], and Fiji Melanesians (Zimmet and Taylor, unpublished data) show that diabetes is more common in non-obese urban dwellers than rural dwellers of similar weight. Rural people are usually engaged in occupations having higher levels of physical activity, and it may be this factor that protects them against diabetes. Differences in diabetes prevalence occurred in the male population of Fiji between those who were graded sedentary or light activity, compared with the group graded as moderate or heavy activity. These differences were maintained after age adjustment [12].

If exercise is a candidate as a protective factor for diabetes, then there is clearly a need for much more detailed study of its relationship to diabetes prevalence and incidence.

Dietary factors: Diet has been thought to contribute to the development of diabetes in two ways: Firstly, through the supply of calories and resultant obesity if activity is low; and secondly, via the effects of specific foods. These two actions of diet can be referred to as the quantitative effect and the qualitative effect.

Quantitative effect: One of the most important differences in the diet available in industrialized countries compared with traditional agricultural or subsistence societies is the high calorie density (calorie/weight ratio) of manufactured food. A combination of energy density and low fibre means that there is a high calorie intake per weight of food eaten, and yet because of the low fibre it takes a lot of food to produce satiety. Both these factors contribute to a high total calorie intake and, in turn, to obesity.

Qualitative effect: It has been suggested that dietary factors, e. g. composition of diet independent of obesity may have a role in precipitating diabetes in a genetically susceptible individual. The automatic choice for such a qualitative role - and one that has received much attention - is the possibility that diabetes is related to consumption of refined carbohydrates. The information about this possibility is controversial and conflicting. Indeed, West [4] lists 21 reports in support and 22 reports against sugar consumption causing diabetes. In fact, the epidemiological information in terms of proper population studies is sparse and there are enormous difficulties in determining whether relationships between increasing sugar consumption and increasing diabetes frequency are coincidental or causally related. The classic examples cited in the literature are sugar cane-cutters who consume high quantities of sucrose [79]. On the other hand, these workers are lean and they engage in heavy manual labour - two factors that may protect against diabetes.

Yudkin [80] and Cohen and Teitelbaum [81] have presented evidence that high sucrose intake might be diabetogenic. However, several population studies have found no evidence to support this. Indeed, in one of these studies, Keen was unable to show a diabetogenic role of carbohydrate intake or total calorie intake [82].

In recent years, lack of dietary fibre has been suggested as a diabetogenic factor [83]. Again, with modernization of diet and lifestyle, a reduction of dietary fibre is just one of many components in this change. Thus, epidemiological information on the relationship between low dietary fibre and diabetes is inconclusive, and such a relationship can only be inferred. Several authors have given strong arguments that there is a negative relationship between dietary fibre and diabetes [83, 84]. However, until studies are carried out where the effects of dietary fibre can be studied in isolation as a risk factor for diabetes and there are improved analytical techniques for the measurement of dietary fibre, no conclusive statement is possible.

There is also no evidence to implicate directly dietary fat, protein, or other nutrients as definite aetiological factors in human diabetes [4]. However, these and, of course, carbohydrates may be diabetogenic through enhancing the risk of obesity. Nor is there evidence to implicate preservatives used in tinned foods and drinks, although the possibility cannot be ruled out.

Toxins: Environmental factors such as toxins have been shown to cause B cell damage and induce dia- 
betes. Vacor, a rodenticide, has been responsible for human diabetes in over 20 reported cases [85]. Helgason and Jonasson have provided circumstantial evidence to implicate the $\mathrm{N}$-nitroso-compound content of processed mutton in the production of ketosisprone diabetes in Iceland [86]. There also appears to be an epidemiological association between cassava consumption and the geographical occurrence of tropical malnutrition diabetes [87]. Cassava contains cyanide-yielding substances and it has been suggested that combination of protein malnutrition along with cyanide causes toxic damage to the pancreas. Animal studies appear to confirm the link [87].

Socio-economic status and diabetes: There is certainly considerable anecdotal and epidemiological information (dating from an ancient Indian Sanskrit) to suggest that diabetes is a disease of the rich. In many developing nations, diabetes has been reported to be more common in the ruling or upper-class families, e.g. the Zulu Royal family and the Tongan Royal family, and West cites many more examples [4]. This increased prevalence could be due to many factors, e.g. more frequent testing, obesity, reduced physical activity, consanguinity. West et al. determined diabetes prevalence rates by class in Central America [88]. In those with moderate income and relatively privileged social status, diabetes was about four times more common that in the poor.

Parity: Earlier studies suggested that there was a strong positive relationship between parity and diabetes $[89,90]$. These earlier studies were mainly hospital-based and more recent population-based epidemiological studies have failed to confirm the association $[88,91]$. On the other hand, Middleton and Caird found a positive association in an English community [92].

The well demonstrated physiological effects of pregnancy on carbohydrate metabolism would suggest a diabetogenic role. On the other hand, in many populations the prevalence of diabetes is not increased in women. While this does not exclude parity as a causative factor, the evidence from most populations suggests that parity plays a minor role.

Psycho-social stress due to modernization: Apart from changes in customs, diet and exercise patterns, the change to a cash economy by the migrant brings certain potential stresses. It is very difficult to assess what contribution stress might have in precipitating diabetes in people with a genetic susceptibility to the disease. Even more difficult is the measurement of stress. However, the possibility that stress may be a diabetogenic factor cannot be ignored and is perhaps one of a number of factors which, in varying degrees of magnitude, have a role in causing the high diabetes prevalence.

There is an increasing interest in the concept of central nervous system control of insulin secretion [93]. It has been suggested that neuro-transmitter substances, such as somatostatin, may play an important role and this raises important and exciting questions as to how centrally mediated stimuli, such as stress, may play a role in the aetiology of diabetes.

The new information on the role of the central nervous system in energy regulation and metabolism is exploding and may have important implications in relation to obesity and diabetes [94]. Woods et al. have reported that the intraventricular injection of betaendorphin causes an increase in meal size of $50 \%$ over $30 \mathrm{~min}$ in rats [95]. Porte and Woods [96] noted that when insulin was infused into the lateral ventricles of free feeding baboons, a dose-dependent suppression of food intake and body weight occurred. These, and other recent developments, may provide us with a greater understanding of the interaction of stress, the nervous system, appetite control and diabetes.

\section{Conclusion}

A naïve concept of diabetes epidemiology is that it is mainly concerned with screening and case-finding. Clearly, this is not the true situation and epidemiological studies have played an important role in the development of the classification and diagnostic criteria for diabetes. They have, through descriptive epidemiology, provided information on prevalence, incidence, and natural history of Type 1 and Type 2 diabetes and their complications. Analytical epidemiology has added to our understanding of the risk factors and host characteristics in the aetiology of both forms of diabetes. Beyond the scope of this review, but just as important, are experimental epidemiology and clinical trials which evaluate prevention and treatment programmes for diabetes and its complications.

Almost certainly Type 2 diabetes when considered on a worldwide basis is a heterogeneous disorder. Type 2 diabetes in certain populations, e.g. the Pimas and Nauruans, may be different from that in Caucasoids, although there is very little scientific evidence to support this.

Epidemiologists, and indeed all diabetologists, must seize the special opportunities presented by high prevalence Type 2 diabetic groups, inter-ethnic comparisons, and migration studies to define the diabetic genotype(s) and the environmental risk factors. At present, the risk factors are becoming increasingly clear although there may be other, as yet undefined, 
factors which have not been covered by this review. The search for the genotype(s) gives the promise of great rewards and is still a very open area. However, it gives promise of being able to define subjects at risk of developing Type 2 diabetes. There is evidence that Type 2 diabetes is at least partly reversible with calorie restriction and weight reduction [97]. Given that our knowledge of environmental risk factors will eventually be complete, there is hope that a large percentage of cases of Type 2 diabetes can be prevented.

\section{References}

1. Bennett PH, LeCompte PM, Miller M, Rushforth NB (1976) Epidemiological studies of diabetes in the Pima Indians. Recent Prog Horm Res 32:333-376

2. Zimmet P, Guinea A, Guthrie W, Taft P, Thoma K (1977) The high prevalence of diabetes mellitus on a Central Pacific island. Diabetologia 13: 111-115

3. Zimmet P, Arblaster M, Thoma K (1978) The effect of westernization on native populations. Studies on a Micronesian community with a high diabetes prevalence. Aust NZ J Med 8: $141-146$

4. West KM (1978) Epidemiology of diabetes and its vascular complications. Elsevier, New York

5. Gamble D (1980) The epidemiology of insulin dependent diabetes with particular reference to the relationship of virus infection to its etiology. Epidemiologic Reviews 2: 49-70

6. National Diabetes Data Group (1979) Classification and diagnosis of diabetes mellitus and other categories of glucose intolerance. Diabetes 28: 1039-1057

7. World Health Organization Expert Committee on Diabetes Mellitus, Second Report (1980), Technical Report Series 646, WHO Geneva

8. Neel JV (1976) Diabetes mellitus: A geneticist's nightmare. In: Creutzfeld W, Koberling J, Neel J (eds) The genetics of diabetes mellitus. Springer, New York, pp 1-11

9. Zimmet $\mathbf{P}(1980)$ When is diabetes? - A new look at diagnostic criteria for diabetes mellitus. Aust NZ J Med 10:346-350

10. West KM(1974) Diabetes in American Indians and other native populations of the New World. Diabetes 23: 841-855

11. Zimmet P(1979) Epidemiology of diabetes and its macrovascular complications in Pacific populations: The medical effects of social progress. Diabetes Care 2:144-153

12. Taylor R, Zimmet $P$ (in press) The epidemiology of diabetes migrant studies. In: Mann J, Pyorala K, Teuscher A (eds) Diabetes - a clinical perspective. Churchill Livingstone, Edinburgh

13. Prior IAM, Davidson F (1966) The epidemiology of diabetes in Polynesians and Europeans in New Zealand and the Pacific. NZ Med J 65:375-383

14. Zimmet P, Ainuu S, DeBoer W, Faaiuso J, Whitehouse S (1981) The prevalence of diabetes in the rural and urban Polynesian population of Western Samoa. Diabetes 30: 45-51

15. Irvine WJ (1980) Autoimmunity in diabetes. In: Waldhäusl W (ed) Diabetes 1979. Excerpta Medica, Amsterdam, pp 353-366

16. Editorial (1977) The epidemiological transition. Lancet 2: 670

17. Mouratoff GJ, Carroll NV, Scott EM (1967) Diabetes mellitus in Eskimos. JAMA 199: 107-112

18. Mouratoff GJ, Carroll NV, Scott EM (1969) Diabetes mellitus in Athabaskan Indians in Alaska. Diabetes 18:29-32

19. Gupta OP, Dave SH, Joshi MH (1978) Prevalence of diabetes in India. In: Levine R, Luft R (eds) Advances in metabolic disorders, vol 9. Academic Press, New York, pp 13-28
20. Toyota T, Goto Y, Komatsu K, Kudo M, Taya S (1976) Prevalence of diabetes in rural and urban Japan. In: Baba S, Fukui S, Goto Y (eds) Diabetes mellitus in Asia. Excerpta Medica, Amsterdam, pp 35-40

21. Djokomoeljanto R, Boedhi-Darmojo R, Hamardji, Soetardjo (1976) A community study of diabetes mellitus in an urban population in Semarang, Indonesia. In: Baba S, Fukui S, Goto Y (eds) Diabetes mellitus in Asia. Excerpta Medica, Amsterdam, pp 45-50

22. Shanghai Diabetes Research Cooperative Group (1980) Diabetes mellitus survey in Shanghai. Chinese Med J 93: 663-672

23. Cheah JS, Tan BY (1979) Diabetes among different races in a similar environment. In: Waldhäusl W (ed) Diabetes 1979. Excerpta Medica, Amsterdam, pp 512-516

24. Welborn TA, Cullen KJ, Curnow DH, McCall MG, Stenhouse NS, Wearne JT (1968) Diabetes detected by blood sugar measurement after a glucose load: Report from the Busselton survey, 1966. Med J Aust 2: 778-783

25. Henry RE, Bennett PH, Burch TA, Miller M (1969) Diabetes in the Cocopah Indians. Diabetes 18:33-37

26. Stein JH, McDonald GW, Robey JM, Tirador DF, West KM (1965) The high prevalence of abnormal glucose tolerance in Cherokee Indians of North Carolina. Arch Intern Med 116: $842-846$

27. Prior IAM, Beaglehole R, Davidson F, Salmond CE (1978) The relationship of diabetes, blood lipids, and uric acid levels in Polynesians. In: Levine R, Luft R(eds) Advances in metabolic disorders, vol 9. Academic Press, New York, pp 242-260

28. Wise PH, Craig R, Edwards FM, Elliot RB, Hatcher L, Thomas DW (1970) Hyperglycaemia in the urbanized aboriginal. The Davenport survey. Med J Aust 2: 1001-1006

29. Martin FIR, Griew AR, Haurahelia M, Higginbotham L, Wyatt GB (1980) Diabetes mellitus in urban und rural communities in Papua New Guinea. Studies of prevalence and plasma insulin. Diabetologia 18: 369-374

30. Zimmet P, Kirk RL, Serjeantson S, Taylor R, Whitehouse S (in press) Diabetes in Pacific populations - genetic and environmental interaction in diabetes mellitus. In: Baba S, Melish J (eds) Diabetes in Asia and Oceania. Excerpta Medica, Amsterdam

31. West KM, Kalbfleisch JM (1966) Glucose intolerance in Uruguay, Venezuela, Malaya and East Pakistan. Diabetes 15:9-18

32. Marine N, Edelstein O, Jackson WPU, Vinik AI (1969) Diabetes hyperglycaemia and glycosuria among Indians, Malays and Africans (Bantu) in Cape Town, South Africa. Diabetes 18: $840-857$

33. Zammit Maempel JV (1965) Diabetes in Malta. A pilot survey. Lancet 2: 1197-1200

34. Sanchez-Medina M (1979) Special needs of Latin America. Diabetologia Croatica VIII (Suppl) 1:135-141

35. Stern MP, Allen CR Jr, Garza V, Gonzales JL, Parten Gaskill S, Waldrop RH (1981) Cardiovascular risk factors in Mexican Indians in Laredo, Texas. 1. Prevalence of overweight and diabetes and distribution of serum lipids. Am J Epidemiol 113: $546-555$

36. Bose RKC (1907) Comments on diabetes in the tropics. B med J 2: $1053-1054$

37. Jackson WPU (1978) Diabetes in South Africa. In: Levine R, Luft R (eds) Advances in metabolic disorders, vol 9. Academic Press, New York, pp 111-146

38. Williams E, Williams P (1981) Uganda West Nile district. In: Trowell HC, Burkitt DP (eds) Western diseases: their emergence and prevention. Edward Arnold, London, pp 188-193

39. Trowell HC (1981) Hypertension, obesity, diabetes mellitus and coronary heart disease. In: Trowell HC, Burkitt DP (eds) Western diseases: their emergence and prevention. Edward Arnold, London, pp 3-32 
40. Poon-King T, Henry MV, Rampersad F (1968) Prevalence and natural history of diabetes in Trinidad. Lancet 1:155-160

41. Prior I, Tasman-Jones C (1981) New Zealand Maori and Pacific Polynesians. In: Trowell HC, Burkitt DP (eds) Western diseases: their emergence and prevention. Edward Arnold, London, pp 227-267

42. Cohen AM, Bavly S, Poznanski R (1961) Change of diet in relation to diabetes and ischaemic heart disease. Lancet 2: 1399-1401

43. Cohen AM, Chen B, Eisenberg S, Fidel J, Furst A (1979) Diabetes, blood lipids, lipoproteins and change of environment. Restudy of the "new immigrant Yemenites' in Israel. Metabolism 28:716-728

44. Kawate R, Nishimoto Y, Yamakido M (1980) Migrant studies among the Japanese in Hiroshima and Hawaii. In: Waldhäusl WK (ed) Diabetes 1979. Excerpta Medica, Amsterdam, pp 526-531

45. Bennett PH, Knowler WC (1980) Increasing prevalence of diabetes in the Pima (American). Indians over a ten year period. In: Waldhäusl WK (ed) Diabetes 1979. Excerpta Medica, Amsterdam, pp 507-511

46. West KM, Kalbfleisch JM (1970) Diabetes in Central America. Diabetes 19:656-663

47. Harris M (1982) The prevalence of diagnosed diabetes, undiagnosed diabetes and impaired glucose tolerance in the United States. In: Melish JS, Hanna J, Baba S (eds) Genetic environmental interaction in diabetes mellitus. Excerpta Medica, Amsterdam, pp 70-76

48. Hamman RF, Bennett PH, Miller M (1978) Incidence of diabetes among the Pima Indians. In: Levine R, Luft R (eds) Advances in Metabolic Disorders, vol 9, Academic Press, New York, pp 49-63

49. Knowler WC, Bennett PH, Hamman RF, Miller M (1978) Diabetes incidence and prevalence in Pima Indians: A 19-fold greater incidence than in Rochester, Minnesota. Am J Epidemiol 108: 497-504

50. Palumbo PJ, Labarthe DR (1978) The incidence of diabetes mellitus in Rochester, Minnesota, 1945-1969. In: Levine R, Luft R (eds) Advances in metabolic disorders, vol 9. Academic Press, New York, pp 13-20

51. Zimmet P, Pinkstone G, Thoma K, Whitehouse S (1982) The high incidence of diabetes mellitus in the Micronesian population of Nauru. Acta Diabetologica Latina (in press)

52. Rushforth NB, Bennett PH, Burch TA, Miller M, Steinberg AG (1971) Diabetes in the Pima Indians. Evidence of bimodality in glucose tolerance distributions. Diabetes 20:756-764

53. Zimmet P, Whitehouse S (1978) Bimodality of fasting and twohour glucose tolerance distributions in a Micronesian population. Diabetes 27: 793-800

54. Rushforth NB, Bennett PH, Miller M (1979) Fasting and twohour post-glucose levels for the diagnosis of diabetes. The relationship between glucose levels and complications of diabetes in the Pima Indians. Diabetologia 16:373-379

55. Hayner NS, Epstein FH, Francis T, Kjelsberg MD (1965) Carbohydrate tolerance and diabetes in a total community: Tecumseh, Michigan. Diabetes 14: 413-423

56. Cudworth AG, Woodrow JC (1975) Evidence for HL-A-Linked genes in "juvenile" diabetes mellitus. B med J 3: 133-135

57. Christy M, Christau B, Green A, Kromann H, Nerup J, Platz P, Ryder L, Svejgaard A, Thomsen M (1979) Studies of the HLA system and insulin-dependent diabetes mellitus. Diabetes Care 2: 209-214

58. Pyke DA (1979) The genetic connection. Diabetologia 17: 333-343

59. Serjeantson S, Court J, Dry PJ, Kirk RL, Ryan DP, Stepanas AV, Zimmet P(1980) HLA studies in Australian multiple-case families of juvenile onset diabetes mellitus. Med J Aust 1: 107-109

60. Owerbach D, Nerup J (1981) Restriction fragment length polymorphism of the insulin gene in diabetic individuals. Diabetologia 21:311 (Abstract)

61. Cruz-Vidal M, Costas R, Garcia-Palmieri MR, Hertsmark E, Sorlie PD (1979) Factors related to diabetes mellitus in Puerto Rican men. Diabetes 28:300-307

62. Neel JV (1962) Diabetes mellitus: a thrifty genotype rendered detrimental by 'progress'? Am J Hum Genet 14: 353-362

63. Neel JV (in press) The thrifty genotype revisited In: Kobberling J, Tattersal R (eds) The genetics of diabetes mellitus. Proc Serono Symposium. Academic Press, London

64. Wise PH (1977) Significance of anomalous thermo-regulation in the pre-diabetic spiny mouse (Acomys Cahirinus): Cold tolerance: Blood glucose and food consumption responses to environmental heat. Aust J Exper Biol Med Sci 55: 475-484

65. Zimmet $P$, Kiss J, Whitehouse $S$ (1979) Ethnic variability in insulin secretion. Diabetes 28: 624-628

66. Wise PH, Craig RJ, Edwards FM, Evans B, Murchland JB, Sutherland B, Thomas DW (1976) Diabetes and associated variables in the South Australian aboriginal. Aust NZ J Med 6: 191-196

67. Kobberling J, Bengseh N, Bruggeboes B, Schwarch K, Tillil H, Weber B (1980) The chlorpropamide alcohol flush. Diabetologia 19: $359-363$

68. Briggs BR, Botha MC, Jackson WPU, Du Toit ED (1980) The histocompatibility (HLA) antigen distribution in South African blacks (Xhosa). Diabetes 29:68-70

69. Williams RC, Bennett PH, Butler WJ, Johnson AH, Knowler WC, Lisse JR, Mann DL, Pettit DJ, Teraski PI (1981) HLA-A2 and Type 2 (insulin independent) diabetes mellitus in Pima Indians: An association of allele frequency with age. Diabetologia $21: 460-463$

70. Cudworth AG (1978) Type 1 diabetes mellitus. Diabetologia 14: 281-291

71. Rotter JI, Rimoin DL (1979) Diabetes mellitus: the search for genetic markers. Diabetes Care 2:215-226

72. Knowler WC, Bennett, PH, Pettit PJ, Savage PJ (1981) Diabetes incidence in Pima Indians: Contributions of obesity and parental diabetes. Am J Epidemiol 113:144-156

73. Zimmet $P$, Whitehouse $S$ (1979) The effect of age on glucose tolerance. Studies in a Micronesian population with a high prevalence of diabetes. Diabetes 28: 617-623

74. DeFronzo RA (1981) Glucose intolerance and ageing. Diabetes Care 4: 493-501

75. Medalie JH, Goldbourt U, Herman JB, Papier CM (1978) Variations in the incidence of diabetes among 10,000 adult Israeli males and factors related to their development. In: Levine R, Luft R (eds) Advances in metabolic disorders, vol 9. Academic Press, New York, pp 94-110

76. Taylor, R, Whitehouse S, Zimmet P(1982) Is the role of obesity as a risk factor for diabetes overstated? Studies in rural and urban Polynesians (Western Samoa). In: Melish JS, Hanna J, Baba S (eds) Genetic environmental interaction in diabetes mellitus. Excerpta Medica, Amsterdam, pp 179-183

77. Ahuja M (1976) Vicissitudes of epidemiological studies of diabetes mellitus. J All India Inst Med Sci 2: 5-13

78. Barnett AH, Eff C, Leslie RDG, Pyke DA (1981) Diabetes in identical twins. A study in 200 pairs. Diabetologia 20: 87-93

79. Campbell GD, Batchelor EL, Goldberg MD (1967) Sugar intake and diabetes. Diabetes 16:62-63

80. Yudkin J (1964) Dietary fat and dietary sugar in relation to ischemic heart disease and diabetes. Lancet 2: 4-5

81. Cohen AM, Teitelbaum A (1966) Effect of different levels of protein in "sucrose" and "starch" diets on the glucose tolerance and growth. Metabolism 15: 1034-1038 
82. Keen H (1974) Diabetes and sugar consumption. In Hillebrand SS (ed) Proc 8th Symposium of International Sugar Research Federation, Bethesda, Maryland, USA, pp 14-17

83. Trowell H(1975) Dietary-fiber hypothesis of the etiology of diabetes mellitus. Diabetes 24:762-765

84. Cleave TL (1974) The saccharine disease. Wright, Bristol, UK

85. Rossini AA, Appel MC, Like AA, Mordes JP, Williams RM (1980) Animal models of insulin dependent diabetes. In: Waldhäusl WK (ed) Diabetes 1979, Excerpta Medica, Amsterdam, pp 367-372

86. Helgason T, Jonasson MR (1981) Evidence for a food additive as a cause of ketosis-prone diabetes. Lancet 2: 716 720

87. McMillan DE, Geevarghese PJ (1979) Dietary cyanide and tropical malnutrition diabetes. Diabetes Care 2: 202-208

88. West KM, Kalbfleisch JM (1971) Influence of nutritional factors on prevalence of diabetes. Diabetes 20:99-108

89. Pyke DA (1956) Parity and the incidence of diabetes. Lancet 1 : $818-821$

90. Fitzgerald MG, Malins JM, O'Sullivan DJ, Wall M (1961 a) The effect of sex and parity on the incidence of diabetes mellitus. $J$ Med 30:57

91. Zimmet P, Collins J, Currie P, DeBoer W, Seluka A, Wicking J (1977) Diabetes mellitus in an urbanized isolated Polynesian population. The Funafuti Survey. Diabetes 26:1101-1108
92. Middleton GD, Caird FI (1968) Parity and diabetes mellitus. Br J Prev Soc Med 22: 100-104

93. Steffens AB (1981) The modulatory effect of the hypothalamus on glucagon and insulin secretion in the rat. Diabetologia 20 (Suppl) 411-416

94. Porte D Jr, Berthoud HR, Jeanrenaud B, Woods SC (1981) Diabetes and the nervous system. Diabetologia 20 (Suppl): 245 (Editorial)

95. Woods SC, Kenney NJ, Lotter EC, McKay LD, Porte D Jr, Porte SG, Stein LJ, West DB (1981) Peptides and the control of meal size. Diabetologia 20 (Suppl): 305-313

96. Porte D Jr, Woods SC (1981) Regulation of food intake and body weight by insulin. Diabetologia 20 (Suppl): 274-280

97. Savage PJ, Bennion LJ, Bennett PH (1979) Normalization of insulin and glucagon secretion in ketosis-resistant diabetes mellitus with prolonged diet therapy. J Clin Endocrinol Metab 49: $830-833$

Assoc. Professor Paul Zimmet

WHO Collaborating Centre for the Epidemiology

of Diabetes Mellitus

Royal Southern Memorial Hospital

Caulfield 3162, Victoria, Australia 